Cahiers $d u$ MONDE RUSSE

\section{Cahiers du monde russe}

Russie - Empire russe - Union soviétique et États indépendants

$51 / 4 \mid 2010$

Sciences humaines et sociales en Russie à l'Âge d'argent

\title{
Carole Ferret, Une civilisation du cheval
}

\section{Charlotte Marchina}

\section{(2) OpenEdition}

12 Journals

\section{Édition électronique}

URL : https://journals.openedition.org/monderusse/7455

DOI : 10.4000/monderusse. 7455

ISSN : $1777-5388$

\section{Éditeur}

Éditions de l'EHESS

\section{Édition imprimée}

Date de publication : 25 novembre 2010

Pagination : 830-833

ISBN : 978-2-7132-2316-7

ISSN : $1252-6576$

\section{Référence électronique}

Charlotte Marchina, «Carole Ferret, Une civilisation du cheval », Cahiers du monde russe [En ligne], 51/4 | 2010, mis en ligne le 09 décembre 2011, consulté le 03 septembre 2022. URL : http:// journals.openedition.org/monderusse/7455; DOI : https://doi.org/10.4000/monderusse.7455

Ce document a été généré automatiquement le 3 septembre 2022

Tous droits réservés 


\title{
Carole Ferret, Une civilisation du cheval
}

\author{
Charlotte Marchina
}

\section{RÉFÉRENCE}

Carole FERRET, Une civilisation du cheval. Les usages de l'équidé de la steppe à la taïga. Paris : Belin, 2010, 350 p.

1 Cet ouvrage imposant de Carole Ferret, tiré de sa thèse de doctorat en ethnologie ${ }^{1}$, est une véritable mine pour qui s'intéresse aux chevaux dans cette région du monde. L'erreur serait de croire qu'il ne s'adresse qu'à un public amateur d'équidés. En effet, l'auteur procède à une anthropologie de la relation à un animal, le cheval, qui envahit toutes les sphères du social et du culturel, aboutissant à une conception équine du monde. Ces civilisations des steppes, ou "civilisations du cheval», si elles semblent depuis longtemps évocatrices au public occidental, n'ont néanmoins pas fait l'objet de descriptions approfondies. Que ce livre soit le premier ouvrage détaillé sur la question peut sembler étonnant. À cela deux explications : d'une part, depuis la fin de l'URSS, une nouvelle génération de chercheurs se penche davantage sur les questions politiques ou religieuses, au détriment des «cultures matérielles », dont l'étude est parfois considérée comme moins «noble»; d'autre part, une telle recherche exige compétences et connaissances dans les domaines de l'équitation et de l'hippologie.

2 L'ethnologue et cavalière expérimentée qu'est Carole Ferret a ainsi, une quinzaine d'années durant, collecté une masse considérable d'informations en alternant séjours prolongés sur le terrain et recherches en bibliothèques sur un vaste territoire de l'exURSS. Le lecteur ne peut être qu'impressionné par l'aire géographique couverte, que l'auteur désigne par l'expression d'« Asie intérieure »: Iakoutie, Kazakhstan, Kirghizstan, Turkménistan, Ouzbékistan, Touva, Khakassie, Bouriatie. Sans compter les nombreuses autres ethnies citées, répertoriées à la fin de l'ouvrage. L'auteur adopte une approche 
comparative de ces cultures altaïques, avec quelques références aux civilisations mongoles, tout en approfondissant le cas des Iakoutes, cas limite de la culture turcique.

Outre les données de première main, fruit d'une véritable observation participante chez les éleveurs, on appréciera la grande diversité des matériaux utilisés (sources archéologiques, historiques, zoologiques, littérature de voyage, études ethnographiques, iconographie...), ainsi que les qualités de polyglotte de l'auteur (un glossaire reprend les termes indigènes fréquemment utilisés).

Dans sa méthode d'analyse des données ethnographiques, Carole Ferret sépare la production (input), de la consommation au sens large (output) de l'animal. Le présent ouvrage ne traite que du second aspect, c'est-à-dire des usages du cheval, la production faisant l'objet d'un autre ouvrage ${ }^{2}$. S'inspirant de l'anthropologue François Sigaut, l'auteur classe les utilisations du cheval altaïque en trois grandes catégories : produits corporels (ch. II et III), énergie (IV) et signes (V), ce qui permet de ne pas dissocier le matériel du symbolique et de privilégier le moyen d'action sur la fin.

Dans le premier chapitre («Vieux comme le mammouth»), l'auteur étudie l'évolution et la répartition du cheptel. D'une manière générale, le nombre de chevaux par habitant, bon indicateur de l'ampleur de sa diffusion, a considérablement diminué. Non sans avoir surmonté les difficultés d'ordre méthodologique qu'induit la manipulation de données chiffrées et statistiques parfois contradictoires, Carole Ferret montre que la part de l'espèce équine dans le cheptel s'est réduite. Enfin, l'analyse de l'évolution de la composition $\mathrm{du}$ cheptel équin indique une restriction de l'usage du cheval: traditionnellement polyvalent, celui-ci s'est transformé en un simple produit.

La seconde partie du chapitre montre " l'invention du cheval iakoute ». En effet, ce petit équidé au métabolisme hors du commun (il reste dehors toute l'année, dans le pays le plus froid de l'hémisphère Nord) a été l'objet de nombreux débats sur son origine dans les années 1970-1980 : a-t-il été importé ou est-il aborigène? L'ethnologue étudie les deux hypothèses, mais met surtout l'accent sur les enjeux idéologiques d'une telle controverse. De nombreux travaux ont cherché à mettre en valeur le cheval iakoute, d'une part par son ancienneté, d'autre part par son originalité ou au contraire par son universalité. Dans une ex-URSS obsédée par la question des origines, problème éminemment politique, certains n'ont pas hésité à procéder à une assimilation fallacieuse entre formation des races de chevaux et genèse des peuples. Les Iakoutes $\mathrm{y}$ étaient d'autant plus sensibles que l'hypothèse de leur arrivée tardive sur le territoire actuel représentait une menace pour leur légitimité. L'année 1987 voit donc la création officielle de la race du cheval iakoute. Or, fait original, la race est définie par son usage, créant ainsi une identité presque parfaite entre race et territorialité (est de race iakoute tout cheval présent sur le territoire, qui n'appartient pas à une autre race). La logique de valorisation et de distinction du cheval, ainsi que la création de la race mettent en valeur la nation iakoute (au point qu'une silhouette de cavalier sert d'emblème à la république de Iakoutie dès qu'elle déclare son autonomie, en 1990), ce qui permet à l'auteur de parler d'une véritable « invention » du cheval iakoute.

7 L'un des faits saillants du deuxième chapitre est que le cheval altaïque peut être rapproché du porc occidental : de la même façon que chez nous, « dans le cochon tout est bon», pour les Iakoutes, "dans le cheval tout est un régal». Dans le cas du cheval iakoute, la polyfonctionnalité est particulièrement étendue. Toutefois, l'orientation résolument productiviste de l'élevage équin fait que le cheval vaut davantage par les produits qu'il fournit que par son énergie. En effet, sa viande occupe une place de 
première importance dans la cuisine iakoute. L'auteur passe en revue les plats de la boucherie chevaline, les modes de cuisson de cette viande, les formes spécifiques de consommation (interdits alimentaires pour certaines catégories de personnes ou encore consommation rituelle) et ses vertus médicinales en Asie intérieure. Si le régime alimentaire des pasteurs altaïques est carné l'hiver, il repose sur les produits laitiers l'été. Le lait de jument, consommé uniquement sous sa forme fermentée, kumys, est considérée comme la boisson reine chez les éleveurs turco-mongols. De l'invention de ce breuvage à son déclin chez les Iakoutes, l'auteur dresse un tableau détaillé de son histoire, en passant par une description des récipients et ustensiles propres au kumys, de ses techniques de fabrication, de conservation et de ses innombrables vertus. Si, chez les Iakoutes, cette boisson est aujourd'hui essentiellement consommée dans un cadre festif, lors de la fête nationale, initialement conçue comme une cérémonie de libations de kumys (l'auteur nous livre une riche description de ces festivités, du xvi siècle à nos jours), elle est encore très présente dans le quotidien des pasteurs centrasiatiques. On retiendra que, pour les Iakoutes, manger du cheval est, en quelque sorte, une manière d'assimiler un être vénéré; on notera également quelques remarques pleines de vie, telles que " asséner à quelqu'un: "L'outre à kumys de ton grand-père était un estomac de chien", c'est l'injurier» (p. 120), ou encore qu'" être traité de "soupe de tripes" est un compliment en iakoute, puisque l'expression [...] désigne une personne aimable et prévenante » (p. 88).

Le troisième chapitre (" Laineux comme un mouton») est dédié aux autres produits, non alimentaires, que fournit le cheval chez les peuples altaïques. La densité exceptionnelle ainsi que la finesse du poil du cheval iakoute permettent de qualifier cet équidé "d'animal à fourrure». Suit un inventaire comprenant les procédés de fabrication des produits de pelleterie (chaussures, chapkas, moufles, sacs, tapis...), de cuir (bottes, récipients, pièces de harnais...) et à base de crins (cordes, filets, tamis, lunettes de soleil, émouchoirs...), ces derniers étant parfois également considérés comme une offrande privilégiée, tout comme les crânes, suspendus en hauteur. Os, tendons, sabots et excréments sont tout autant recyclés, à des fins variées. Certaines sécrétions (urine, sueur, salive) étaient utilisées dans des buts thérapeutiques. Ainsi, ce sont toutes les parties du cheval qui sont utilisées pour se nourrir, se guérir, s'habiller ou encore s'outiller.

9 Comparé à ce qu'est le dromadaire aux étendues désertiques, le cheval est le "vaisseau de la steppe et de la taïga » (ch. IV). En Asie intérieure, c'est en effet le premier moyen de transport. Autrefois instrument de conquête du territoire, le cheval est couramment utilisé comme bête de somme encore de nos jours. L'auteur consacre quelques belles pages aux techniques de bât, de conduite des caravanes et aux qualités des chevaux de bât. Mais le cheval est avant tout un animal de selle, en particulier dans les sociétés pastorales centrasiatiques où tout un chacun monte à cheval. Carole Ferret décrit les techniques de monte, les harnais iakoutes et centrasiatiques de l'Antiquité à nos jours, ainsi que les allures. Siège comme un autre, le cheval monté permet en outre la surveillance du bétail, ainsi qu'une forme de chasse équestre; il a joué un rôle décisif dans l'art de la guerre, notamment chez les Scythes. Les compétitions hippiques, qui accompagnent un mouvement de renouveau national récent dans cette région, telles les courses ou le kôkpar (jeu équestre où les participants se disputent une dépouille caprine), sont extrêmement populaires. Enfin, plus rarement, le cheval peut être employé comme animal de trait ou instrument de foulage. Aujourd'hui encore, la latéralisation du monde qu'a induite la monte est évidente : la gauche est désignée par « le côté du montoir », la droite par « le côté où on tient le fouet » (p. 174). À cela s'ajoute une certaine conception 
de l'espace, en ce sens que de nombreuses unités de mesure sont conçues en référence à l'équidé.

Dans le dernier chapitre, Carole Ferret montre comment le cheval est « une vache à l'envers ». Contrairement à la vache, physiquement proche et symboliquement éloignée de l'humain, le cheval se fait plus discret de nos jours dans la vie quotidienne des Iakoutes mais conserve une place éminente dans leur culture. Indice de richesse, le cheval fait l'objet d'une thésaurisation, mais c'est aussi une unité de compte pour évaluer les compensations matrimoniales ou les dédommagements judiciaires. Les chevaux circulent : ils sont échangés, prêtés, vendus, donnés et volés (le vol de bétail peut même engendrer un certain prestige, en particulier lorsqu'il s'inscrit dans une suite de vols et de contre-vols). De multiples sacrifices font intervenir le cheval (accompagnement du défunt dans la tombe, sacrifice aux esprits, consécration...). Le cheval envahit enfin la langue par les très nombreuses locutions qui lui font allusion, mais est aussi un motif récurrent dans l'artisanat et peut aller jusqu'à servir d'emblème national.

11 Cet ouvrage, par ses descriptions ethnographiques précises et minutieuses, ainsi que ses très nombreuses illustrations fort utiles, revêt des caractéristiques quelque peu encyclopédiques: c'est que l'auteur s'efforce de rendre son travail accessible au grand public. Le livre de Carole Ferret n'en constitue pas moins un apport majeur dans le domaine de l'anthropologie des relations entre hommes et animaux, en montrant comment, tout particulièrement dans le cas des sociétés pastorales, l'étude du rapport à l'animal est révélatrice de tout un mode de rapport aux humains.

\section{NOTES}

1. «Techniques iakoutes aux confins de la civilisation altaïque du cheval. Contribution à une anthropologie de l'action ", thèse EHESS, sous la direction de Jean-Pierre Digard, 2006.

2. Carole Ferret, Techniques d'élevage et de dressage du cheval en Asie intérieure. Contribution à une anthropologie de l'action, Louvain : Peeters [à paraître]. 